\title{
Pathomorphological changes of aceclofenac toxicity in layer chicks
}

\author{
N. J. Patel, B. P. Joshi, K. S. Prajapati and V. M. Patil \\ Department of Veterinary Pathology, \\ College of Veterinary Science and Animal Husbandry, Anand Agricultural University, \\ Anand-388001, Gujarat, India. \\ Corresponding author: N. J. Patel, email: nikitajpatel88@yahoo.in
}

Received: 20-12-2013, Revised:17-01-2014, Accepted: 27-01-2014, Published online: 24-02-2014

doi: 10.14202/vetworld.2014.90-94

How to cite this article: Patel NJ, Joshi BP, Prajapati KS and Patil VM (2014) Pathomorphological changes of aceclofenac toxicity in layer chicks, Veterinary World 7(2): 90-94.

\begin{abstract}
Aim: The present research work was undertaken to study the patholomorphogical changes induced by repeated doses of aceclofenac.

Materials and Methods: 100 BV-300 day old layer chicks were randomly divided into four equal groups and treated with aceclofenac at the dose rate of $0,10,20$ and 30 ppm orally through feed for 21 consecutive days.

Results: The abnormal behavioral clinical signs like dullness, lethargy, lameness, anorexia, feather plucking and uneven growth were noticed only in chicks of treatment groups III and IV with varied severity. Maximum mortality was observed in group IV (16\%) followed by group III (4\%). A dose dependent reduction in body weight was found in all the treatment groups. Grossly, on surface of visceral organs white chalky urate deposits of varying degree were observed in chicks which died during experiment from treatment groups III and IV. Histopathologically, the lesions were characterized by congestion, degeneration, haemorrhage and deposition of uric acid crystals. Kidney was the main target organ affected.
\end{abstract}

Conclusion: The present study indicates that aceclofenac is hepatotoxic as well as nephrotoxic which causes visceral gout in layer chicks.

Keywords: aceclofenac, hepatotoxic, layer chicks, nephrotoxic, visceral gout, toxicity

\section{I ntroduction}

A recent study showed that aceclofenac is a potential threat to critically endangered vultures in India [1]. Despite the ban on diclofenac in veterinary practice, other non-steroidal anti-inflammatory drugs such as aceclofenac, ketoprofen, carprofen, flunixin meglumine, meloxicam, phenylbutazone etc. are still widely used. Vultures feeding on the carcasses of recently treated livestock with aceclofenac suffer acute kidney failure within few days of exposure and show the same toxic effect when fed on the carcasses of animals treated with diclofenac. As a result, aceclofenac might also be contributing to further decline of the remaining vulture population. Researchers formerly thought that aceclofenac would not be as harmful because it is metabolized faster by cows, and converted within hours into a product that is not dangerous to avian species, but with recent advancements scientists found that doses given to cattle in India were sufficient to kill the birds. Hinz et al [2] showed that aceclofenac could slowly but sustainably biotransform into diclofenac. Aceclofenac is lethal to birds in the doses that would be administered to livestock to reduce pain and swelling due to rheumatism or arthritis. Poultry feed also contains many animal source byproducts like meat and bone meal, blood

Copyright: The authors. This article is an open access article licensed under the terms of the Creative Commons Attribution License (http://creativecommons.org/licenses/by/2.0) which permits unrestricted use, distribution and reproduction in any medium, provided the work is properly cited. meal, bone based DCP, mutton tallow etc. which are likely to have aceclofenac residues and are probably responsible for visceral gout in birds. Birds' being uricotelic and lacking the enzyme uricase, the end product of protein metabolism is uric acid and therefore birds have the potential to develop gout. Uric acid is produced by the liver and excreted through the kidneys. The condition occurs as a consequence of severe renal dysfunction, where a reduction in renal filtration leads to an increase in the blood uric acid levels [3].

Thus, to further understand the toxic effects of aceclofenac, we conducted the present study to elucidate by administering aceclofenac at variable doses to commercial layer chicks.

\section{Materials and Methods}

Ethical approval: The prior approval from the Institutional Animal Ethical Committee was obtained for use of the animals in this study.

Chemicals and experimental animals: Aceclofenac in tablet form containing $100 \mathrm{mg}$ of the active drug per tablet was used for the present investigation. The study was conducted on day old BV-300 layer chicks. A total of 100 BV-300 layer chicks were procured from a local commercial hatchery (Shakti Hatcheries Pvt. Ltd., Sarsa, Anand, Gujarat, India) and were maintained under standard managemental conditions. Layer chicks were kept in cages and housed in the Experimental Unit, Department of Veterinary Pathology, College of 


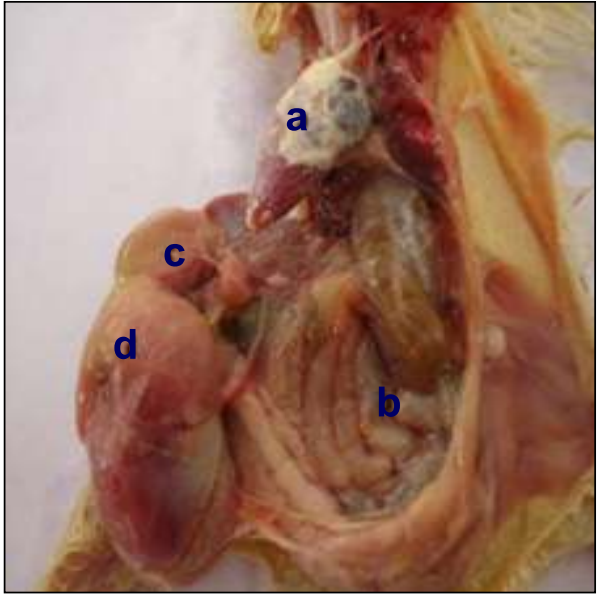

Figure-1. Layer chick died from group IV showing white urate deposition on the surface of pericardium (a), abdominal air sacs (b), proventriculus (c) and gizzard (d).

Veterinary Science and Animal Husbandry, Anand. Environmental temperature and lighting regimens were applied according to the BV-300 guidelines.

Determination of the dose: Aceclofenac is less potential than diclofenac and most of the studies were conducted in animals, especially in lab animals (mice and rat) and has been not yet conducted in layer chicks. Aceclofenac is structurally and pharmacologically closely related to diclofenac. Hence the dose used during this study was double that of the previous diclofenac study on broiler chicks [4].

Experimental design: The day old 100 layer chicks were randomly divided into four different groups, comprising of 25 chicks in each group. Aceclofenac tablet was crushed to fine powder and mixed in the mash feed in graded levels for inducing toxicity in BV300 layer chicks. The groups II, III and IV were given graded doses of aceclofenac at the rate of $10 \mathrm{ppm}$ (low dose), $20 \mathrm{ppm}$ (mid dose), $30 \mathrm{ppm}$ (high dose), respectively through feed every day for 21 consecutive days where as group I served as control and fed only layer mash feed without aceclofenac. Weighing of chicks was done at weekly intervals. Mortality and morbidity were recorded throughout the experimental period. After completion of the experiment, the surviving birds from all the four groups were subjected to a terminal sacrifice by means of the cervical dislocation. The postmortem examination of each bird from different groups was performed and gross lesions were recorded. Tissue samples from organs like kidney, liver, heart, lung, spleen and intestine were collected in $10 \%$ formalin for histopathological examination. The tissue pieces from kidney and liver were fixed in absolute alcohol and were stained using De-Galantha's special staining method for demonstration of urate crystals. The different parameters like clinical signs, mortality, body weight, kidney: body weight ratio, feed consumption, feed conversion ratio (FCR) were studied.

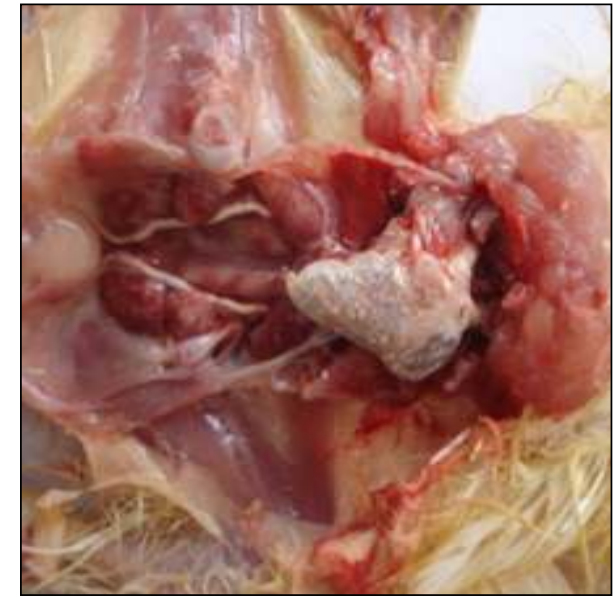

Figure-2. Layer chick died from group IV showing white chalky urates deposition on pericardium and enlarged frosted kidneys with dilated ureters filled with urates.

Statistical analysis: The data obtained from feed consumption, body weight and mortality were subjected to one way ANOVA test where a $p<0.05$ was considered as statistically significant and $p<0.01$ as highly significant.

\section{Results and Discussion}

Chicks under group I and II did not reveal any observable clinical signs whereas chicks of groups III and IV showed similar clinical signs which gradually became more pronounced in group IV. Birds exhibited a tendency to remain standing at one place with apathy, unthriftiness with ruffled feathers, dullness and drooping of the wings. Birds appeared emaciated, dehydrated, depressed and lethargic with shrunken eyes. They also exhibited signs like anorexia, feather plucking and uneven growth. Such birds showed shifting leg lameness and inability to stand. Most of the clinical signs observed in aceclofenac treated chicks were in conformity with earlier reports in layer chicks $[5,6]$. In albino rats, aceclofenac caused gastro intestinal ulcers and gastro intestinal bleeding leading to anaemia [7] whereas Darbar et al [8] observed depression, anorexia, jaundice, fever and nausea due to acute hepatitis following exposure to aceclofenac in rats. Maximum mortality was observed in group IV (16\%) followed by group III (4\%). In group IV mortality started from day 16 onwards and was continued up to day 19 whereas in group III it started on $19^{\text {th }}$ day after aceclofenac treatment. Similar results were observed by Sehgal et al [9] and Reddy et al [10]. The dose dependent reduction in body weight was observed in all the treatment groups. At the end of $1^{\text {st }}$ week only group IV showed significant $(\mathrm{p}<0.05)$ decrease in body weight. The groups III and IV showed significant reduction in body weight at the end of $2^{\text {nd }}$ week. At the end of $3^{\text {rd }}$ week group III showed significant whereas group IV showed highly significant $(\mathrm{p}<0.01)$ reduction in body weight as compared to the control. The mean values of kidney: body weight ratio were 


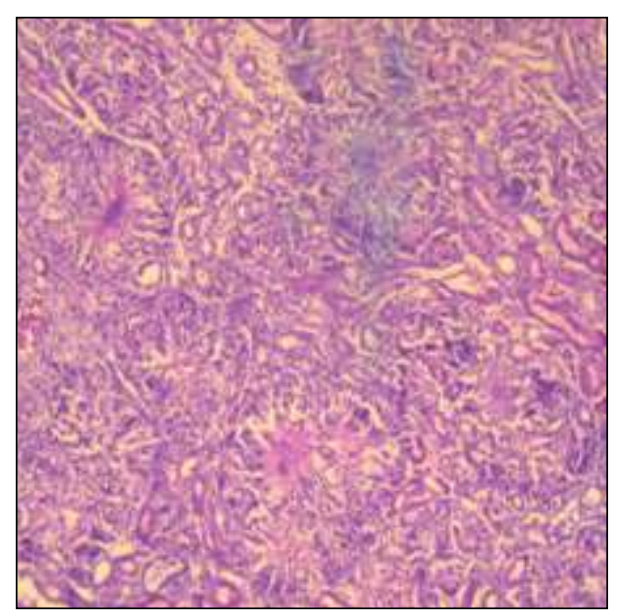

Figure-3. Section of kidney from chick died of group III showing marked deposition of needle shaped uric acid crystals in renal parenchyma.

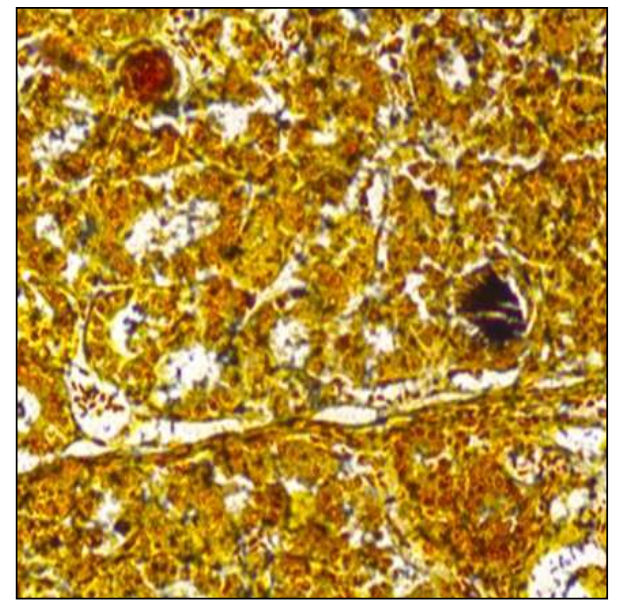

Figure-5. Section of kidney from chick died of group IV showing deposition of black uric acid crystals in renal parenchyma. De galantha's X 300 .

significantly increased in groups III and IV as compared to the control. There was reduction in the feed consumption observed in group IV followed by group III and II when compared to control during the entire experimental period. Shinde [11] observed similar results in broiler chicks. The average FCR calculated at the end of experiment was higher in treatment groups as compared to control. Highest FCR of 1.84 was observed in group IV followed by 1.82 in group III, 1.80 in group II and lowest 1.79 was recorded in group $\mathrm{I}$.

Post mortem examination of birds which died during the experiment showed emaciation and dehydration with deposition of white urates in the form of dry platery patches over various visceral organs upon opening the abdomen (Fig-1). The affected kidneys were more enlarged and frosted with chalky white urate deposits and pin point haemorrages on the surface (Fig-2). Gross pathological lesions of intoxicated layer chicks of the present study were in agreement with the earlier reports of diclofenac and

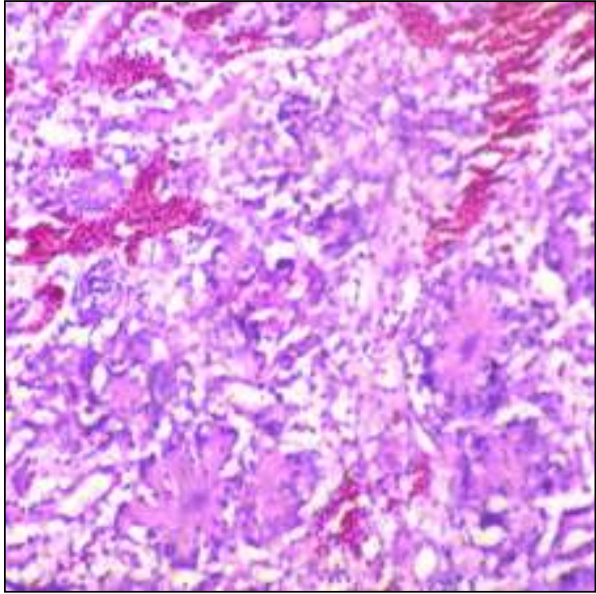

Figure-4. Section of kidney from chick died of group IV showing marked inter tubular haemorrhages, deposition of uric acid crystals degeneration and necrosis of renal tubules. $H \& E X 300$.

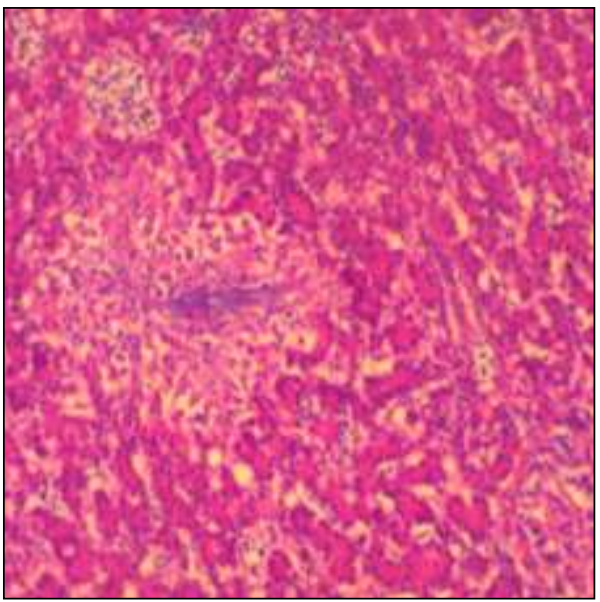

Figure-6. Section of liver from chick died of group IV showing deposition of uric acid crystals in hepatic parenchyma. $\mathrm{H} \& \mathrm{EX}$ 300.

ketoprofen sodium induced toxicity changes in layer and broiler chicks [12,13]. Microscopically, kidney lesions showed mild to moderate congestion, intertubular haemorrages, parenchymatous degeneration, necrosis of tubules and deposition of uric acid crystals (Fig-3 and 4) which appeared black with degalantha's staining (Fig-5). Madhuri et al [14], Meteyer et al [15], Mulcahy et al [16] and Naidoo et al [17] have reported similar results related to kidney during their studies. The kidney lesions of the nature of gouty nephritis with uric acid and urates deposition were also reported by Irtaza et al [18], Sharma and Vegad [19] and Senthil kumar and Thirumurugan [20]. Liver from the dead birds showed presence of chalky white deposits on its surface. Deposition of chalky white urate crystals on the liver, a diagnostic feature of visceral gout was also reported by Jana et al [21]. Microscopically, liver lesions were characterized by necrosis of hepatic cells and infiltration of heterophils and mononuclear cells with focal deposition of uric acid crystals (Fig-6). Focal uric acid crystals were also visible as black 


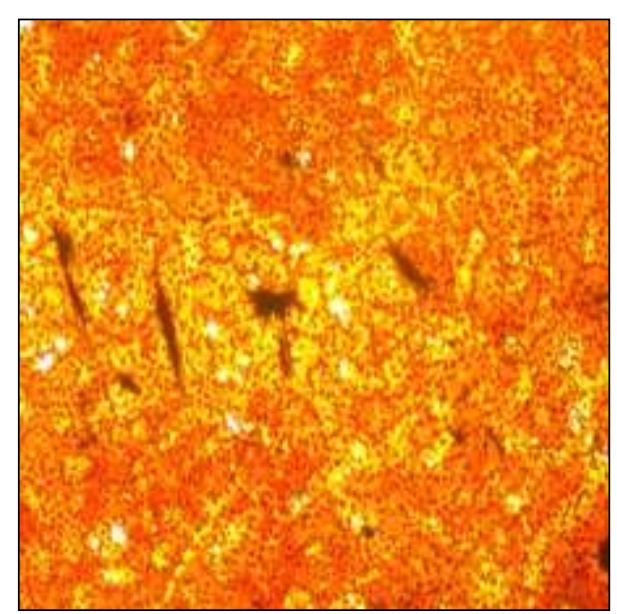

Figure-7. Section of liver from chick died of group IV showing deposition of black uric acid crystals in hepatic parenchyma. De Galantha's X 300.

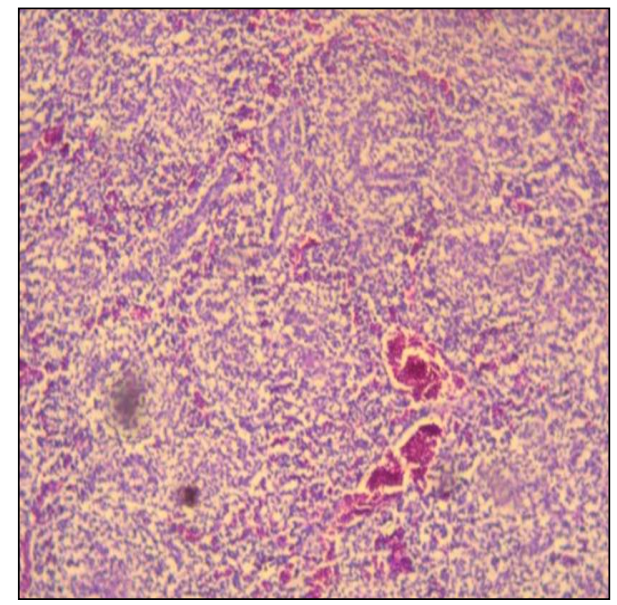

Figure-9. Section of spleen from chick died of group IV showing depletion of lymphoid cells. H\&EX 150.

radiating mass with De-galantha's stain (Fig-7). Myocardium of the heart showed urate deposition along with destruction of myocardial cells and infiltration of inflammatory cells mainly mononuclear cells (Fig 8). Deposition of chalky white urate on the pericardium of heart in visceral gout was observed by Mir et al [22], Patel [23] and Shultz et al [24]. Splenic lesions consisted of congestion of splenic parenchyma with focal or multifocal area of necrosis and mild to moderate depletion of lymphocytes (Fig-9). Lung lesions were characteristic of mild to moderate congestion and focal to diffuse haemorrhages in the alveolar parenchyma (Fig-10). Such lesions were also noticed by Uma et al [25].

\section{Conclusion}

Aceclofenac administered at the dose of greater than $20 \mathrm{ppm}$ induces toxicity symptoms in layers. Pathomorphological lesions induced by aceclofenac toxicity were of vascular and degenerative in nature mainly affecting kidney, liver, heart, proventriculus, gizzard, spleen, lung and intestine and were specific of

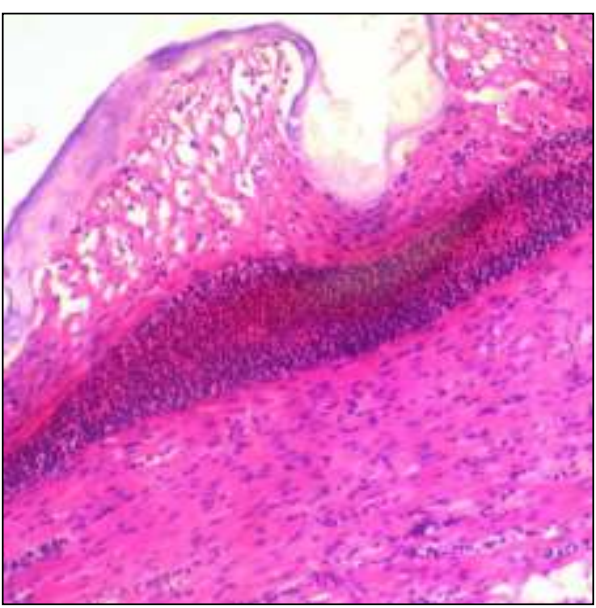

Figure-8. Section of heart from chick died of group IV showing severe engorgement of blood vessel in the cardiac parenchyma along with uratic deposition on the pericardium (arrow). H\&EX 300

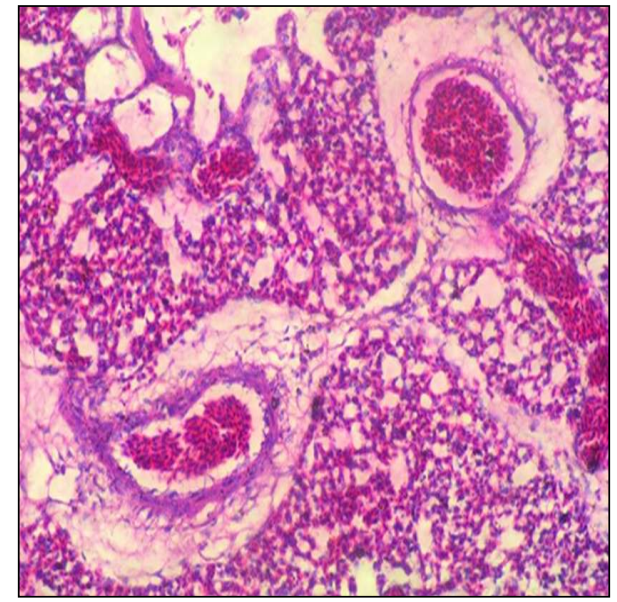

Figure-10. Section of lung from chick died of group IV showing moderate congestion and focal to diffuse haemorrhages in alveolar parenchyma. $H \& E X 300$.

visceral gout. Aceclofenac administration at and above 20 ppm for 21 days induces visceral gout in layer chicks.

\section{Authors' contributions}

NJP: conducted research work, experimental design, gross and histopathological identification and drafted the manuscript. BPJ and KSP: provided guidance during entire experiment and revised and corrected the manuscript. VMP: performed histopathological work. All authors read and approved the final manuscript.

\section{Acknowledgements}

This study was funded by College of Veterinary Science and Animal Husbandry, Anand Agricultural University, Anand, Gujarat, India. The authors are thankful to all staff of Department of Veterinary Pathology, College of Veterinary Science and Animal Husbandry, Anand Agricultural University, Anand, Gujarat, India for their help.

\section{Competing interests}

The authors declare that they have no competing interests. 


\section{References}

1. Sharma, P. (2012) Aceclofenac as a potential threat to critically endangered vultures in India: A Review. Journal of RaptorRes. 46 (3): 314-318.

2. Hinz, B., Rau, T., Auge, D., Werner, U., Ramer, R., Rietbrock, S. and Brune, K. (2003) Aceclofenac spares cyclooxygenase 1 as a result of limited but sustained biotransformation to diclofenac. Clin Pharmacol Ther. 74(3): 222-235.

3. Oaks, J. L., Gilbert, M., Virani, M. Z., Watson, R. T., Meteyer, C. U., Rideout, B., Shivaprasad, H. L., Ahmed, S., Chaudhry, M. J., Arshad, M., Mahmood, S., Ali, A. and Khan, A. A. (2004) Diclofenac residues as the cause of vulture population decline in Pakistan. Nature. 427: 630633.

4. Gajera, A. B. (2006) M.V. Sc. thesis. Pathological studies on experimental feeding of diclofenac sodium in broilers, Anand Agricultural University, Anand.

5. Ghanvat, D. P. (2012) M.V. Sc. thesis. Toxicopathological studies of ketoprofen in layer chicks, Anand Agricultural University, Anand.

6. Jain, T., Koley, K. M., Vadlamudi, V. P., Gosh, R. C., Roy, S., Tiwari, S. and Sahu, U. (2009) Diclofenac induced biochemical and histopathological changes in white leghorn birds (Gallus domesticus). Indian J Pharmacol. 41(5): 237241.

7. Tamta, A., Payasi, A., Chaudhari, M., Ahmed, A. and Dwivedi V. (2009) Sub acute toxicity of aceclofenac drug in albino rat. Iranian Journal of Toxicology. 2 (3): 240-245.

8. Darbar, S., Bhattacharya, A., Chakraborty, M. and Chattopadhyay, S. (2010) Livina, a polyherbal preparation protects liver against aceclofenac-induced hepatic insult in sprague-dawley rats: a comparison with silymari. Pharmacol Online. 2: 889-907.

9. Sehgal, R., Bhatia, P. and Arora, P. (2011) Sub-chronic toxicological evaluation of aceclofenac in rats. Pharma Scimonit. 2(3): 62-72.

10. Reddy, N. C., Anjaneyulu, Y., Sivasankari, B. and Rao, K. A. (2006) Comparative toxicity studies in birds using nimesulide and diclofenac sodium. Environ Toxicol Pharmacol 22(2):142-147.

11. Shinde, A. S. (2008) M.V.Sc thesis. Pathomorphological and immunobiochemical studies on induced diclofenac sodium toxicity in broiler chicks (gallus gallus domesticus), Sardarkrushinagar Dantiwada Agricultural University, Dantiwada.

12. Seema, A. (2006) M.V.Sc. thesis. Age related pathological effects of diclofenac sodium in poultry, Anand Agricultural
University, Anand.

13. Undhad, V. V. (2012) M.V. Sc. thesis. Toxicopathological studies of ketoprofen in broiler chicks, Anand Agricultural University, Anand.

14. Madhuri, H., Bhandarkar, A. G., Raut, S. S. and Kirit, S. (2008) Experimental diclofenac toxicity in poultry: A pathological study. Indian J. Vet. Pathol. 32(2): 263-266.

15. Meteyer, C. U., Rideout, B. A., Gilbert, M., Shivaprasad, H. L. and Oaks, J. L. (2005) Pathology and proposed pathophysiology of diclofenac in free-living and experimentally exposed oriental white- backed vultures. $J$ Wildl Dis 41 (4):707-716.

16. Mulcahy, D. M., Tuomi, P. and Larsen, R. L. (2003) Differential mortality of male spectacled eiders (Somateria fischeri) and king eiders (Somateria spectablilis) subsequent to anesthesia with Propofol, Bupivacaine, and Ketoprofen. JAvian Med Surg, 17:117-123.

17. Naidoo, V., Wolter, K., Cromarty, D., Diekmann, M., Duncan, N., Meharg, A., Taggart, M., Venter, L. and Cuthbert, R. (2009) Toxicity of non-steroidal anti inflammatory drugs to Gyps vultures: a new threat from ketoprofen. Biol. Lett. 6(3):339-341.

18. Irtaza, H., Khan, M. Z., Khan, A., Ijaz, J. and Kashif, M. S. (2008) Toxicological effects of diclofenac in four avian species. Avian Pathol. 37(3): 315-321.

19. Sharma, R. and Vegad, J. L. (2010) Avian gout: causes, treatment and prevention. Poultry line. 10 (8):19-21.

20. Senthilkumar, K. and Thirumurugan, R. (2005) Visceral gout in a Bengal vulture. Indian Vet. J. 82(7):795-796.

21. Jana, S., Mukhopadhayay, S. K., Niyogi, D., Damodar Singh, Y. and Thiyagaseelan, C. (2009) Epidemiopathological studies of gout in broiler birds in West Bengal. Indian J. Vet. Pathol. 33(2): 222-224.

22. Mir, M. S., Darzi, M. M., Khan, A. A., Ganaie, N. A., Gupta, S., Nashiruddullah, N. and Kamil, S. A. (2005) Investigation of an outbreak of gout in Kashmir Favorella poultry. Indian. J. Vet. Pathol. 29(1):35-37.

23. Patel, A. K. (2005) M.V.Sc. thesis. Epidemiological and experimental studies on etiology of visceral gout in broiler chicks, Anand Agricultural University, Anand.

24. Shultz, S., Baral, H. S., Charman, S., Cunningham, A. A., Das, D., Ghalsasi, G. R., Goudar, M. S., Green, R. E., Jones, A., Nighot, P., Pain, D. J. and Vibhu Prakash (2004) Diclofenac poisoning is widespread in declining vulture populations across the Indian subcontinent. Crossmark. 271(6): 458-460.

25. Uma, C. A., Vijayasarathi, S. K., Nalini, T. S., Satyanarayana, M. L. and Suguna, Rao. (1999) Pathology of gout in poultry. Indian J. Vet. Pathol. 23:94-95. 